\title{
Ethnicity, russification and excess mortality in Kazakhstan
}

\author{
Ethan J. Sharygin and Michel Guillot*
}

\begin{abstract}
Russians experience higher adult mortality than Central Asians despite higher socioeconomic status. This study exploits Kazakhstan's demographic and geographic diversity to study ethnic differences in cause-specific mortality. In multivariate regression, all-cause mortality rates for Russian men is $27 \%$ higher than for Kazakh men, and alcohol-related death rates among Russian men are 2.5 times higher (15\% and 4.1 times higher for women, respectively). Significant mortality differentials exist by ethnicity for external causes and alcohol-related causes of death. Adult mortality among Kazakhs is higher than previously found among Kyrgyz and lower than among Russians. The results suggest that ethnic mortality differentials in Central Asia may be related to the degree of russification, which could be replicating documented patterns of alcohol consumption in non-Russian populations.
\end{abstract}

\section{Introduction}

Russian mortality rates increased dramatically after the fall of the Soviet Union. Russians experienced a severe economic shock and simultaneous rapid decline in life expectancy; it took more than a decade for Russia to recover. Despite experiencing similar economic shocks, non-Russian minorities in former Soviet republics on Russia's periphery seem to have been far less susceptible to the adverse trend in mortality. Hence, the Russian mortality paradox: Russians are often a richer, more educated minority in former Soviet countries, but appear to have worse health outcomes. We discuss the case of Russians in Central Asia to illustrate some of the dynamics of this paradox.

In this paper, we examine the association between russification and excess mortality in Central Asia. We begin by offering new descriptive data on major causes of death by sex and ethnicity in Kazakhstan. We proceed to ask whether Russian language proficiency explains systematic patterns in deaths by ethnicity

* Ethan J. Sharygin (correspondence author), University of Pennsylvania, Population Studies Center, USA. Email: garba@ pop.upenn.edu

Michel Guillot, University of Pennsylvania, Population Studies Center, USA. 
in Kazakhstan and Kyrgyzstan. We find that ethnic Russians in Kazakhstan have higher mortality in than ethnic Kazakhs despite their higher socioeconomic status. This excess mortality is attributable to causes of death related to alcohol, similar to findings in Kyrgyzstan by Guillot et al. (2011b) - confirming the importance of ethnicity in understanding patterns of excess mortality in the region. We also find that ethnic Kazakhs living in more russified areas appear to have higher mortality than those living in less russified areas.

We compare the mortality patterns in Kazakhstan by ethnicity and sex, and compare with results for Kyrgyzstan. We present a behavioural explanation of excess mortality that is compatible with the differences in mortality patterns between Kyrgyzstan and Kazakhstan. We find that excess mortality in Kazakhstan may be driven by a process of diffusion from Russians to Kazakhs, which leads us to conclude that the degree of linguistic russification may be an important factor in explaining mortality variation across Central Asia.

Section 2 begins with a brief demographic background of Kazakhstan and a review of previous papers on Central Asian mortality. This background information is used to formulate hypotheses about the mortality patterns in Kazakhstan, which are presented in Section 3. Section 3 also introduces the data source and methods used in the analysis. In Section 4, we present data on major causes of death by ethnicity and sex. We test the robustness of the ethnic mortality gap through regressions of all-cause and cause-specific mortality. Section 5 concludes with a discussion of greater implications of the findings and directions for future research. For clarity and consistency, the paper uses 'Kazakhs' to refer to Central Asians living in Kazakhstan. We use the term 'Russians in Russia' whenever referring specifically to that population; otherwise, 'Russians' primarily refers to Slavs living in Kazakhstan, and 'Kyrgyz' to refer to Central Asians living in Kyrgyzstan. 'Kazakhstani' or 'Kyrgyzstani' are used as adjectives to refer to the populations of those countries when the context is ambiguous.

\section{Background and related literature}

\subsection{Background}

Kazakhstan is the largest of the Central Asian republics, and shares a border with Russia in the North and China to the East (Figure 1). Russians have had a significant presence in Kazakhstan since the first half of the 19th century. Kazakhstan gradually became integrated into the Russian sphere of influence during this period (Hopkirk 1992, 1995; Meyer and Brysac 2006). Nascent anti-colonial movements during the mid-19th century were suppressed as traders and immigrants moved eastward from European Russia, settling in Kazakhstan and converting land from pastoral to agricultural use. Forced settlement of the nomadic Kazakhs combined with famines 


\section{Figure 1:}

\section{Russian population of Kazakhstan, 1999}

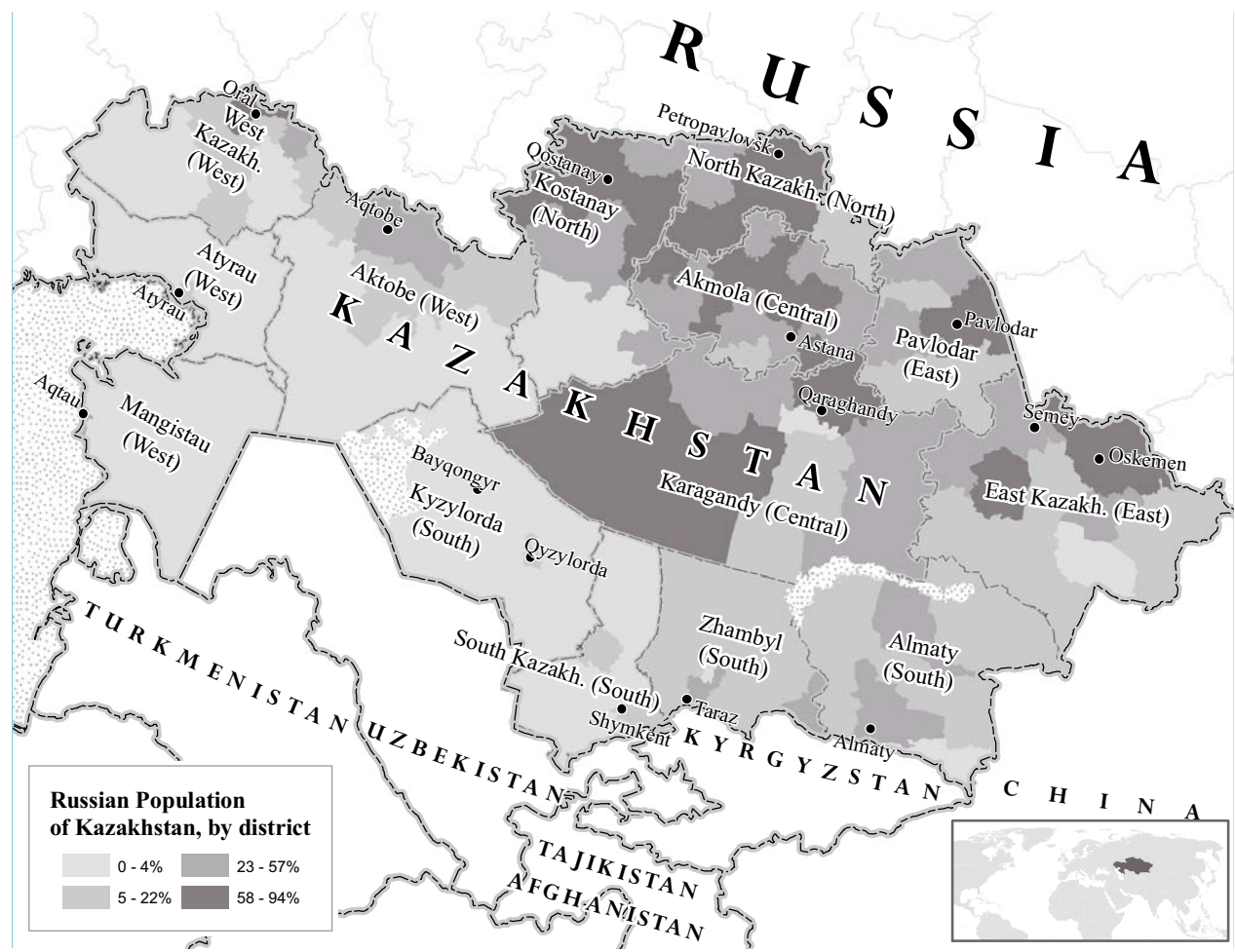

Note: Russian share of total population ages $0-90$ by rayon (district), divided by quartile. Oblast names and boundaries shown with major cities (Almaty and Astana are oblast or province-level cities).

Source: Kazakhstan 1999 Census.

during the 1920s and 1930s took an especially heavy toll on the indigenous population (Peyrouse 2008; Tynystanova 2002).

At the time of the 1999 Census used in this analysis, Russians accounted for nearly $40 \%$ of the population of Kazakhstan. The earliest population count was conducted in 1897, at which time 82 per cent of the population was Kazakh and 11 per cent was Russian. The 1926 Soviet Census recorded that Kazakhs declined to 57 per cent of the population and Slavic groups had grown to 31 per cent. Industrialisation of agriculture and mining and relocation of Soviet political exiles increased the pace of migration into Kazakhstan from other parts of the Soviet Union. The process was accelerated after 1954, as Krushchev's 'Virgin Lands' ('Tseline') policy targeted Kazakh lands as a future center of Soviet grain production. During the years of the program, hundreds of thousands of Russian and Ukrainian migrants settled in the country, mostly dispersed around the northern city of Astana (known as 'Tselinograd' 
during 1961-1991 and capital of Kazakhstan since 1997). By 1959, Kazakhs made up just $30 \%$ of the country's population.

The Kazakh share of the population grew thereafter, but at a modest pace. By 1989 the Kazakhs comprised 40\% of the population, and by the time of the 1999 Census had regained their status as a majority (53\%). This was possible due to the repatriation of large numbers of ethnic Russians, although the remaining Russian population of approximately 4 million still represents over one-fourth of the total population of the country. In 2010, the major Central Asian ethnic groups (Kazakhs, Uzbeks, Kyrgyz) together form 60 per cent of the population. However, several of Kazakhstan's sixteen top-level administrative divisions (called oblasts) are still over $40 \%$ Slavic, as are many more of the lower-level divisions called rayons (Figure 1).

\subsection{Russification of Kazakhstan}

Russification of Kazakhstan was significant but not complete. The adoption of a Cyrillic alphabet and the teaching of Russian made that language nearly universally spoken, while the official Soviet policy of bilingualism preserved Kazakh language teaching in schools. Russian remains a commonly spoken language many years later (at least $68 \%$ of Kazakhs speak it), and continues to be the language in which much of politics, business, and research continue to be conducted. The integration of Russian into Kazakh daily life is suggested by an Uzbek proverb, "if you want to become Russian, first become Kazakh" (Dave 2004).

Kazakhstan may be more russified than other Central Asian states, partly as a result of the greater role in the national economy historically played by Russia and the correspondingly higher share of the population that is non-Kazakh. Still, the Slavic population in Kazakhstan is heterogeneous in its attachment to the Russian cultural mainstream. Russians in the northern and eastern parts of the country tend to identify with Russians in Siberia and the Far Eastern regions of the Russian Federation, while Russians in the south tend to exhibit higher prevalence of Kazakh fluency, which may indicate looser attachment to Russian society (according to the Kazakh 1999 Census, more than $15 \%$ of Russians in the southern region speak Kazakh, compared to a national average of $6 \%$ and less than $1 \%$ in the Slavic strongholds of the north). Russification of urban Kazakhs is pervasive; most Kazakhs in urban areas surveyed throughout the 1980s and 1990s showed very low rates of fluency in Kazakh and little familiarity with Kazakh history (Dave 1996). Dave and Sinnott (2002) suggest that recorded increases in Kazakh fluency may have been overstated and do not reflect very much displacement of Russian language in favour of Kazakh.

Compared to their Central Asian neighbours, Kazakhs have a less healthy diet and drink more alcohol (Cockerham et al. 2004; Waters and Thom 2007). Policy discussions from the late 1990s highlighted increases in alcoholism by the young and women, two groups with very low rates of alcohol consumption prior to independence. Data from the WHO suggest that consumption increased by one fourth, from 8 to 10 liters of alcohol per capita per year between 1995-2000 (Rehm et al. 2004;WHO 
1999). Binge drinking is alarmingly common: the number of times per year that over $220 \mathrm{~mL}$ of vodka is consumed during a single drinking session is 25 in Kazakhstan, compared to 29 in the Russian Federation and just 11 in Kyrgyzstan (Pomerleau et al. 2005). Further survey data finds that Kazakh men who drink consume up to $70 \%$ of their alcohol as vodka, a similar share to Russian men in Kazakhstan (63\%). For both Slavic and Kazakh women, the figure is a still-impressive 45\% (LSMS 1996; author's calculations).

Anthropological literature has long suggested that some features of the nomadic steppe culture have been preserved more completely in Kazakhstan than other Central Asian states (Aristov 1896; Masanov et al. 2002; Radlov 1989). The cultural influence of Islam has also tended to be moderated by the continued presence of traditional steppe culture in both Kazakhstan and Kyrgyzstan - a result of its shorter history in Central Asia, geographic and political isolation, and the suppression of Islamic identity under Communism. The weak influence of conservative Islam is especially true in Kazakhstan, where the majority identify as Muslim but also report widespread indifference to religion and ambivalence about religious practice (Edelbay 2012; Salhani 2011). Common practices in Islamic countries, such as veiling of women, never appeared in Kazakhstan; Waters and Thom (2007) suggest that this is one of several examples of cases where Kazakhs maintained more liberal attitudes than other Central Asian muslims, and that this liberalism resulted in "greater receptivity of the native population to Slav drinking customs than in neighboring regions."

\subsection{The Russian mortality paradox in Central Asia}

Russia's mortality has increased in the decades since the dissolution of the Soviet Union, but its economic standing decreased as well. Mortality trends became increasingly divergent from trends among Central Asians. In some sense, Russians are healthier than expected, since they seem to be just as healthy as those in the Russian Federation, despite Kazakhstan being a significantly poorer country. This observation masks an important deeper paradox, however: Kazakhs are even healthier than Russians, despite being poorer. As shown in Figure 3, age-specific mortality rates for Russians (especially males) is elevated during adult years between ages 20-59 when compared to Kazakhs. The experience of Russians mirrors the Russian Federation remarkably well during this time period. ${ }^{1}$ In recent years, Russian life expectancy has improved. Yet, for the critical transition decade of the 1990s, it remains to be explained why Russians fared so poorly relative to Central Asians.

When significant declines in Russian life expectancy were first noticed, there was a flurry of debate over the competing roles of the decrepitating health care system (Brainerd and Cutler 2005), improvements in the vital statistics reporting system (Anderson and Silver 1997; Andreev et al. 1995; Chen et al. 1996; Gavrilova

1 Validated time series data of ${ }_{n} q_{x}$ do not exist for Kazakhstan, but high correspondence with Russian rates since 1960 is evident in the neighbouring state of Kyrgyzstan (Guillot et al. 2011a). 


\section{Figure 2:}

Ratio of alcohol-related to all-cause mortality, 1999

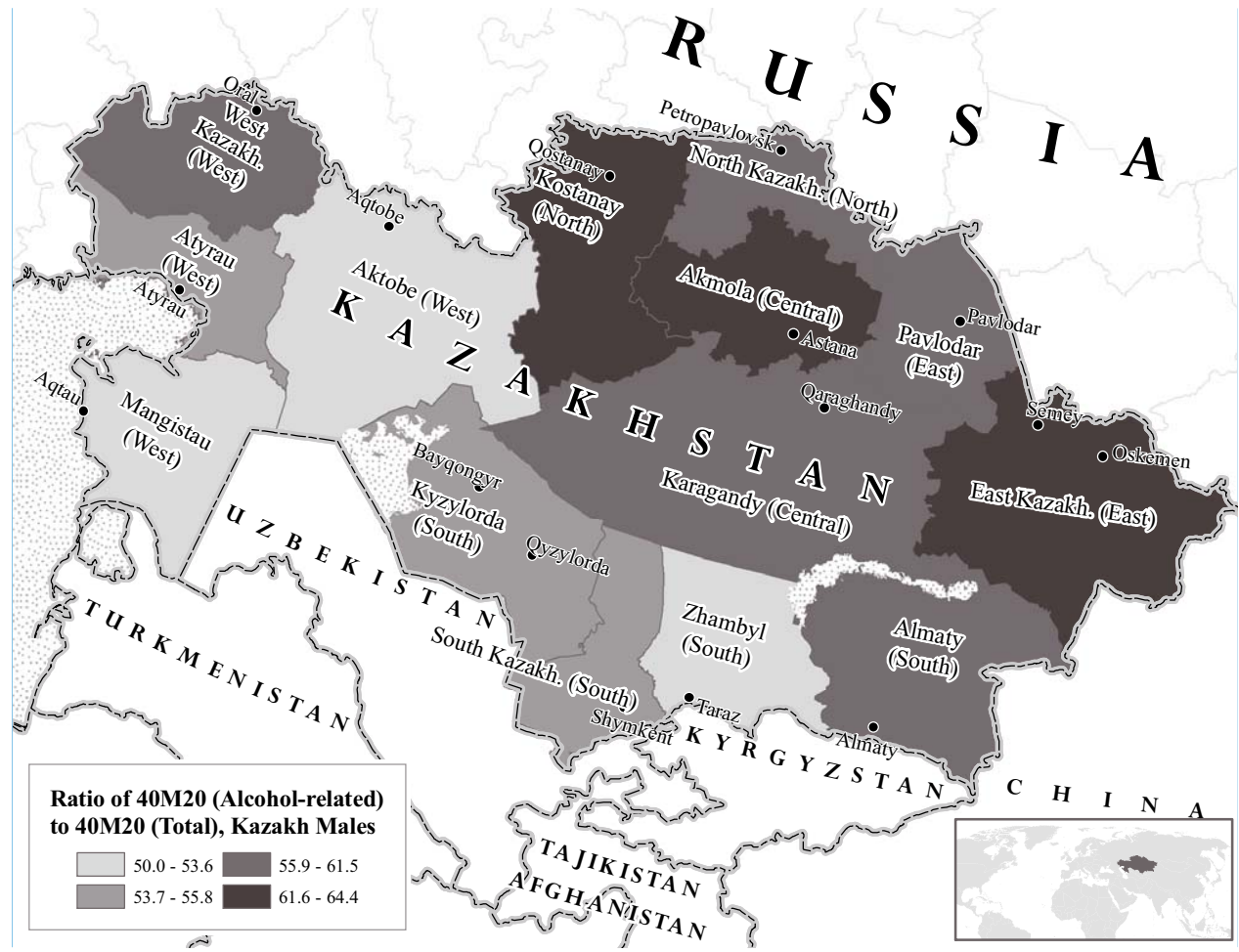

Note: Ratio of mortality rate $\left({ }_{40} M_{20}\right)$ of alcohol-related mortality to ${ }_{40} M_{20}$ for all causes, ethnic Kazakh males. For list of causes considered alcohol-related, see Zaridze et al. (2009a). Oblast names and boundaries shown with major cities (Almaty and Astana are oblast or province-level cities).

Source: Kazakhstan 1999 Census; Kazakhstan Vital Statistics 1998-1999.

7 et al. 2000; Wasserman and Varnik 2007), and the role of cohort dynamicsspecifically, the aging of cohorts that may have been scarred by Russia's turbulent periods of famine and war during 1920-1950 (Avdeev et al. 1998; Willekens and 10 Scherbov 1992). These arguments have gradually given way to recognition that health behaviours are the most likely explanation for Russia's excess mortality. These adverse health behaviours may be due to the poor preparation that the Soviet system gave individuals to self-regulate their health behaviours, combined with the end of Gorbachev's anti-alcohol campaign and the emergence (or re-emergence) of a popular laissez-faire attitude towards alcohol drinking (Avdeev et al. 1998; Brainerd 2010; Cockerham et al. 2004).

According to this literature, trauma from the economic crisis, or indirect consequences of the end of the Soviet system of social and behavioural control, may 


\section{Figure 3:}

Comparative mortality of Russians and Kazakhs, 1999
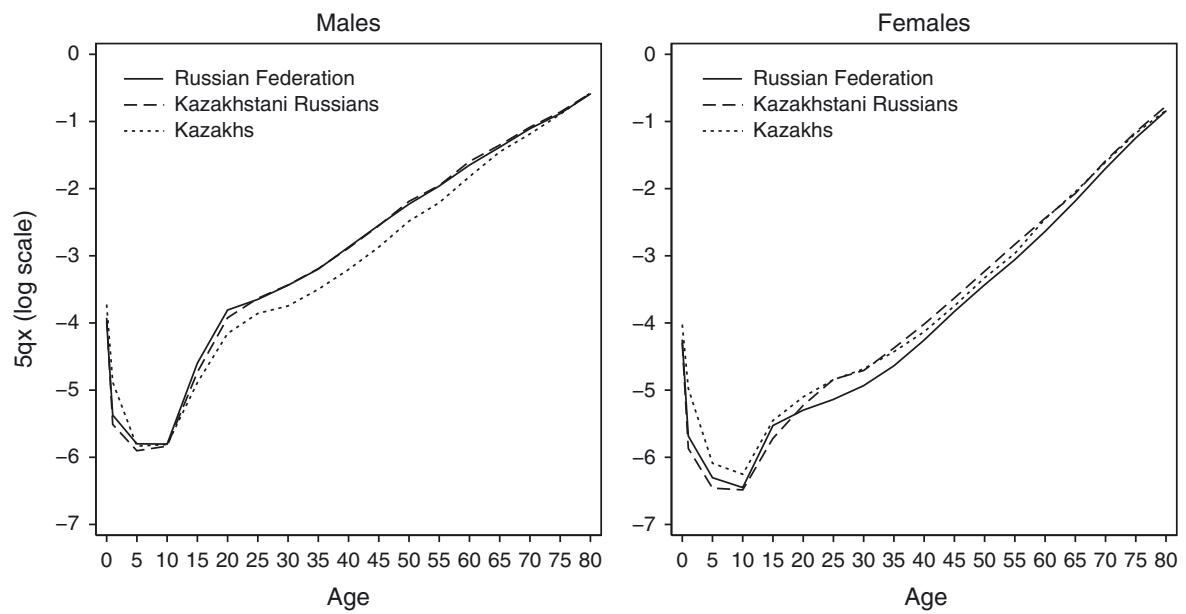

Note: Rates shown as ${ }_{n} q_{x}$, probability of death between age $x$ to $x+n$.

Source: Russia from Human Mortality Database; Kazakhstan from 1999 Census and death certificates microdata 1998-1999.

have spurred drinking. However, this explanation fails to explain why countries in Central Asia took such different trajectories despite similar experiences of transition. The economic crisis was if anything more severe in Central Asia than in Russia. Kazakhstan's economy was bolstered by investment from Russia, and Russia held an effective monopsony on exports of natural resources that completely dissolved after 1989. Although Kazakhstan's economy recovered from these shocks and experienced robust growth starting in the late 1990s, GDP in 2001 was still below the 1989 level (Abbot 2003).

Mortality overall did not increase in Central Asia as much as it did in Russia. Instead, there began to be a divergence between the trends of Central Asians and Slavs, with Slavs following the Russian trend and Asians showing heterogeneous responses to perturbation (Guillot et al. 2011a). New data conclusively shows that the profile of age-specific mortality among Russians mirrors that in Russian Federation more than of other Kazakhstanis (Figure 3), a finding which points to an association between Russian health behaviors and elevated mortality as a potential explanation.

Russians in Central Asia appear to experience higher mortality rates than Kyrgyz (Guillot et al. 2011a) and Kazakhs (Becker and Urzhumova 2005), suggesting that the same behavioural patterns appeared among Russians in Central Asia as in the Russian Federation. However, Cockerham et al. (2004) and Bougdaeva (2010) have argued that the apparent correlation of poor health behaviours with Russian ethnicity in these countries was more a function of age, sex and occupation than of ethnicity per se. Cockerham et al. found that Russian ethnicity was not a significant predictor 
of health status in Kazakhstan after sufficiently controlling for contextual differences. Kazakhs had poorer diet and health habits than Kyrgyz, but comparable to Russians. In fact Cockerham et al. find that Kazakhstani Russians were less likely to be frequent drinkers and more likely to consume vegetables daily than Kazakhs on average after controlling for sex and several socioeconomic characteristics.

Becker and Urzhumova found that the share of oblast population that is Russian is negatively correlated with all-cause mortality during adult ages. However, their analysis relies on oblast-level studies of sex- and age-specific mortality rates, with the per cent of the oblast population that is Russian or Kazakh as a regressor. This approach, while making good use of the data available to the authors, cannot estimate the ethnic mortality gap directly because of correlations between the ethnic composition of an oblast and other correlated characteristics.

We aim to resolve the apparently contradictory findings by using mortality data that is specific by geography, sex, age and ethnicity. In the next section, we introduce hypotheses formed on the basis of the preceding data, and describe the data and methods used in the rest of the study.

\section{Research design}

\subsection{Hypotheses}

If mortality is associated with russification, then Kazakh mortality should be higher than among the Kyrgyz, but below the level of Russians in either country. There should be a smaller gap between Kazakh and Russian mortality in mortality categories where alcohol-related mortality predominates. A greater share of Kazakhstan's population is Russian, so aggregate rates are likely to be higher. If Kazakh mortality is indeed higher than Kyrgyz, we suggest that it may be best explained by russification.

We also expect to find that russified Kazakhs will have higher alcohol-related mortality rates than non-russified. This requires a metric of russification, for which we propose fluency with Russian language. The relevance of Russian fluency to demographic behaviours in Kazakhstan has been previously established (Agadjanian and Dommaraju 2006). In these studies, Kazakhs who were more comfortable speaking Russian than Kazakh tended to have patterns of marriage and fertility behaviours that were more similar to Russians than did other Kazakhs.

This proposition follows from the sociological theories of diffusion and social networks. The process of diffusion or transmission of demographic behaviours became of special interest in the 1970s as a plausible means of interpreting results from detailed studies on the timing of fertility declines in Europe and elsewhere. Fertility change in these large scale studies seemed to follow linguistic and ethnic vectors more closely than economic ones, which many interpreted as supporting the application of diffusion theory to demographic analysis (Cleland and Wilson 1987; Knodel and van den Walle 1979; Lesthaeghe 1977). The leap from transmitting 
contraceptive behaviour to transmitting other relevant behaviours has been made more recently by social network theory. The availability of large scale panel microdata containing detailed information on relationships has enabled studies that have provided evidence for the role of social networks on the spread of behaviours such as smoking, drinking and suicide and outcomes such as obesity and mental health (Smith and Christakis 2008).

Bilingualism enables the transfer of ideas back and forth between individuals, affects the ease of congregation with mixed groups of Russians and Kazakhs, and may affect mortality rates if behaviours related to the ethnic mortality gap are transmitted through socialisation. In their analysis of fertility and contraception, Agadjanian and Dommaraju (2006) go so far as to identify three major ethnic groups in Kazakhstan: Russians, Kazakhs and Kazakhs who usually speak Russian. Although the nature of the available data precludes a direct test of the role of social networks in mortality patterns (we have no data identifying deaths of russified Kazakhs), we can produce an ecological measure of Kazakh russification that should be correlated with mortality.

The logic of diffusion theory is readily applicable to the case of Russians in Kazakhstan. If we consider a simplified world where behavioural norms circulate at the micro level within social networks (which themselves divide along linguistic lines), then a frontier will exist between the Russian-only circles and the Kazakhonly circles populated by those who are fluent in both languages. Although we can only identify the concentration of these groups by geography rather than linking individuals within networks, a greater concentration of Russian-speaking Kazakhs should be associated with more links between Russian-only and Kazakhonly individuals in social networks based there.

Why, in such a world, would ideas not be transmitted equally in both directions between Russians and Kazakhs? One answer might be related to the long history of Russian colonialism in the region. This problem is beyond the scope of the hypotheses at hand, but the anthropological evidence suggests that Russians may be less likely to alter their behaviour in response to interactions with Central Asians than vice versa. For example, mixed households with one Russian parent tend to adopt Russian habits (Edgar 2007); Dave (2007) describes how Russians have propagated their cultural identity by linking themselves to a multinational civic culture rather than geographically and ethnically bounded nationalism. For whatever reason, in this case, the transmission of messaging through social networks seems more important in the direction from Russian to Kazakh than vice versa. Thus, if we assume different starting norms of alcohol consumption among these two groups, then both the static composition of the population as well as the dynamic composition of social networks should both contribute to more prevalence of Russian norms surrounding drinking in areas where more Russians and Russian-speaking Kazakhs are located. ${ }^{2}$

\footnotetext{
2 An alternative explanation relies on the possibility that the decline of the Soviet regime should have directly affected not only Russians, but everyone who was part of the Soviet system. Blum argues that the traditional family system in Central Asia may have been a buffer against both the system of Soviet
} 


\subsection{Methods of analysis}

The goal of the descriptive analysis is to identify the main determinants of the ethnic mortality gap, how they vary by sex and geography, and how the mortality profile compares to Kyrgyzstan. We first compare the value of ${ }_{40} q_{20}$ (the probability of dying between ages 20 and 60) for Slavic and Central Asian men and women. We then compare the mortality rates of Russians and Kazakhs by cause, controlling for sex and for differing age distributions, comparing values of ${ }_{40} M_{20}$ (the age-standardised death rate between ages 20 and 60 ).

This descriptive analysis may strengthen the case for a behavioural interpretation of the Russian mortality paradox, but it cannot determine whether the underlying cause of the mortality gap is behavioural or ecological. Slavs and Central Asians live in very different contexts in Kazakhstan. Although the two groups tend to be equally well educated on average, this outcome masks significant regional interactions between ethnicity, education, and urban-rural residence. In order to determine the extent to which residual ethnic differences remain after accounting for these contextual differences (to the greatest degree possible), we estimate a multivariate regression model of sex-, age-, ethnicity- and geography-specific mortality rates. We estimate a negative binomial regression model with the following basic form: ${ }^{3}$

$$
D_{i j k}=\exp \left[\ln N_{i j k}+\beta_{i} X_{i}+\beta_{j} X_{j}+\sum_{k}\left(\beta_{k} X_{k}\right)+\varepsilon_{i j k}\right],
$$

where $D_{i j k}$ refers to the number of deaths among members of five-year age group $i$ and ethnicity $j$ in oblast $k=1, \ldots, 16, N$ refers to the person-years of exposure and $\varepsilon$ is a error term whose exponential is gamma-distributed. $X$ is a dummy variable indicating membership in group $i, j$, or $k$ and $\beta_{n}$ are the coefficients of interest. We estimate these models separately by sex for three ethnic groups (Slavic, Central Asian and other). We calculate the exposure term using data on person-years lived from the Kazakhstan 1999 Census, and $D$ using death certificates from 1998-99. The analytic sample is limited to 5-year age groups between 20-59.

All models additionally include oblast dummies, in order to account for differences in environment (including economic characteristics). In additional models, we add an urban residence dummy and a set of education level dummies (mid-level education is omitted as the comparison group).

A third model adds a russification measure: the per cent of Kazakhs fluent in Russian, specific to the same oblast and stratified by rural/urban, education level, sex and age group. The model is intended to identify unobserved factors associated

control and the shock of the fall of the Soviet Union that most Russians - and russified Central Asians, to some extent-did not have (Blum 1994, ch. 3).

3 Negative binomial is chosen over customary Poisson model in order to account for heterogeneity within classes, since the data exhibit over-dispersion that violates the assumptions of the Poisson model (Cameron and Trevedi 1990). 
with russification that are uncorrelated with socioeconomic phenomena, so that the lack of further contextual variables is less likely to introduce bias in the estimation of the coefficient. Because language fluency is recorded in the Census but not the deaths data, the measure is environmental rather than demographically specific. The variable used in the regressions is the per cent of Kazakhs who speak Russian in the same age, sex, education level and geographical area (by urban/rural areas within an oblast). Russian fluency among Kazakhs ranges from 48.0-99.9\% across areas, with a weighted mean of $90.6 \%$; the standard deviation is $8.5 \%$, and the distribution is highly negatively skewed. ${ }^{4}$

\subsection{Sources of data}

The main analysis is conducted on mortality rates by age, sex and ethnicity, which are constructed from two sources. Mortality rates used in this analysis are derived from counts of deaths from Kazakhstan's vital statistics death registration system, the vital statistics data cover $90 \%$ of estimated deaths, and only $5 \%$ of deaths are coded according to ill-defined categories (Mathers et al. 2005). Population counts used in this study are from the Kazakhstan 1999 Census. The Census date is near the start of 1999, and therefore mortality rates are calculated using the average the number of deaths by cause observed in 1998 and 1999. ${ }^{5}$ Summary mortality rates are standardised to the European model age distribution to increase the comparability across ethnicities by removing age structure effects. The largest increases in mortality in Kazakhstan during the 1990s appear to have been at adult ages. To narrow our focus to this group, as well as avoid reporting errors likely concentrated in the youngest and oldest age categories, our mortality analysis is limited to ages 20-59.

The rates can be constructed as low as the township level. However, in regressions, we have preferred to use rates calculated at the national and oblast levels, in order to improve the comparability with prior research and also because of the lack of regressors at levels more detailed than oblasts. The contextual variables included in the regression model are taken from the Census, as well as the Demographic and Health Survey (DHS) of 1999 and the Living Standards Measurement Study (LSMS) of 1996 and statistical yearbooks. The death certificates cannot be directly linked to Census records, and therefore only variables existing in both sources can be included in the regression, as well as those which can be linked by geography.

\footnotetext{
4 Although Russian fluency has been validated in some studies as a significant determinant of behavioural differences among Kazakhs (Agadjanian and Dommaraju 2006), some have argued that bilingualism itself may not be a good indicator of russification (Anderson and Silver 1983, 1990). However, the return of Kazakh to public use during the 1990s may reduce the risk that we are capturing what Anderson and Silver term 'unassimilated bilingualism'. To the extent, then, that we find a significant difference, the size of the effect may be underestimated.

5 The Census was conducted 25 February-4 March 1999 (Aisagalieva 1999).
} 
Ethnicity is listed in both death certificates and in the Census, but coded according to slightly different methods. Census ethnicity is self-reported, while death certificates are coded according to the ethnicity listed in the passport of the deceased. To reduce the possibility of mismatch between data sources, comparisons in this paper are made between all Kazakhstani Central Asians (including Kazakhs, Kyrgyz, Uzbeks, Turkmen and Tajiks) and all Eastern Slavs (Russians, Ukrainians and Belorussians). Adults with mixed parentage cannot be identified in the data, a potential source of bias. However, marriages between Central Asians and Slavs are uncommon: tabulations from the 1999 Census data found just $1.2 \%$ of unions were between Russians and Kazakhs. Children of inter-ethnic marriages may choose which official ethnic identity to adopt at age 16; most children with one Russian parent and no Kazakh parent choose to identify as Russian, and a majority of children with one Kazakh parent identify as Kazakh (Dave 2007). As more Russian women intermarry than men, Gorenburg (2006) suggests that ethnic identification may be more closely tied to paternal ethnicity than to ethnic 'allegiance', and thus many children of intermarriages claim official Kazakh ethnicity but have a quintessentially Russian home life. There are significant material incentives to claim Kazakh ethnicity for those who can do so, and a majority of children with Kazakh parentage claim Kazakh identity. However, an independent identity is deeply rooted among Russians; for a fuller discussion of identity and ethnicity, see Dave 2007, pp. 71-95.

Educational categories are also defined differently between the Census and death certificates, so some specificity is lost in the conversion. We have opted to distinguish only between low, medium and high education. Students in Kazakhstan are tracked into higher education after secondary school, into general or specialised/technical education tracks. Low education refers to those with completed primary schooling or below ( $0-6$ years); medium refers to those with junior secondary (6-11 years) or senior secondary education (11-14 years) and high refers to those with partial or completed tertiary education (total 14-19 years).

\section{Results and discussion}

\subsection{Socioeconomic characteristics of Russians and Kazakhs}

The average levels of schooling of Russians and Kazakhs differ by less than 1 year, and the college-educated share of the population does not differ dramatically (Table 1). However, the Russian population is substantially wealthier. The national poverty rate in 1996 was 35\% nationally (30\% in urban and 39\% in rural areas), and the poverty rate by ethnicity was approximately $49 \%$ for Kazakhs and just $21 \%$ for Russians (World Bank 1996). Russian consumption per capita exceeds Kazakhs' by approximately $30 \%$, and to varying degrees in every part of the country. Conventional wisdom might suggest that there should be little difference in mortality rates between 
these two populations based on their socioeconomic characteristics alone, with perhaps a slight edge to Russians as a group on account of their higher income.

The Slavic mortality disadvantage is apparent in Table 1 , as is the very large mortality disadvantage of males overall. Males are more than twice as likely to die between ages 20 and 60 as are females. For Russian males, the ratio is close to two and a half. Russian males on average have 26 per cent higher chance of dying between ages 20 and 60 than Kazakhs, compared to just 9 per cent for Russian females. ${ }^{6}$

\subsection{Cause of death analysis}

Before proceeding to examine the role of contextual factors in explaining the mortality gap, it is useful to determine the causes of death which account for the difference. We will refer frequently to Kyrgyzstan as a comparison case, where causes of death related to Russian patterns of alcohol consumption accounted for 80-85\% of the mortality gap between ethnic Russians and Kyrgyz in 1998-99 (Guillot et al. 2011a).

Cause-specific mortality rates are age-standardised according to the WHO European age standard distribution and separately specified by sex (Table 2). ${ }^{7}$ Results for the main families of causes are reported in Table 2; mortality differentials by detailed cause is in included in the appendix (Table A.1). The gap between Slavic and Central Asian mortality for males in Kazakhstan is approximately 446 deaths per 100,000 population; for females, it is 64 per 100,000. Slavic male mortality is $44 \%$ higher than for Central Asians; female rates are only $15 \%$ higher by comparison. The mortality gap between Russians and Kyrgyz is nearly twice as high for males and approximately equal for females. In Kazakhstan, the greatest share of difference (45\% for males and $78 \%$ for females) is accounted for by external causes of death, which includes accidental and intentional harm from car accidents, poisoning, machinery, falls and suicide and homicide. For males, other causes that explain a significant amount of the gap are circulatory diseases (19.2\%), neoplasms (10.6\%) and infectious diseases $(9.7 \%)$.

We present two ways of examining the role of alcohol in mortality using causeof-death data. The first is by examining 4 causes of death directly attributable to drinking, such as cirrhosis, alcohol psychosis and alcohol poisoning. The second is to examine differences in a list of 35 causes of death indirectly related to alcoholwhere the mortality risk to alcohol users is much higher (Zaridze et al. 2009b). These causes include causes such as violence, accidents and some causes found to

\footnotetext{
6 Differential mortality by urban/rural area is unreliable, due to varying probability of deaths to rural residents being reported in urban areas; for example, if a rural resident dies in an urban hospital.

7 The European model age distribution is chosen to increase comparability with published estimates for Kyrgyzstan. We tested the sensitivity of the estimates to use of a uniform or other age distribution and the results were not affected.
} 
Table 1:

Demographic and economic characteristics of Kazakhstan, 1996-1999

\begin{tabular}{|c|c|c|c|c|c|c|}
\hline Regions: & All & Central & South & West & North & East \\
\hline & \multicolumn{6}{|c|}{ Both sexes, by region } \\
\hline \multicolumn{7}{|l|}{ Kazakhs } \\
\hline Population (1000s) & 8,135 & 1,026 & 3,945 & 1,126 & 567 & 1,472 \\
\hline Per cent urban & 45.4 & 61.4 & 42.8 & 56.2 & 31.5 & 38.2 \\
\hline Consumption per capita & $\$ 683$ & $\$ 746$ & $\$ 484$ & $\$ 749$ & $\$ 1,065$ & $\$ 738$ \\
\hline \multicolumn{7}{|l|}{ Russians } \\
\hline Population (1000s) & 5,398 & 1,235 & 1,632 & 253 & 971 & 1,307 \\
\hline Per cent urban & 72.2 & 81.8 & 69.1 & 82.0 & 58.1 & 75.8 \\
\hline \multirow[t]{2}{*}{ Consumption per capita } & $\$ 1,067$ & $\$ 980$ & $\$ 593$ & $\$ 1,177$ & $\$ 1,367$ & $\$ 1,020$ \\
\hline & \multicolumn{6}{|c|}{ Males, by region } \\
\hline \multicolumn{7}{|l|}{ Kazakhs } \\
\hline Alcohol consumption (mL) & 568 & 574 & 650 & 742 & 707 & 382 \\
\hline Per cent speak Russian & 90.97 & 95.82 & 87.99 & 83.84 & 98.37 & 97.18 \\
\hline Per cent college educated & 10.0 & 12.3 & 11.1 & 7.5 & 9.3 & 8.0 \\
\hline (1) Adult mortality $\left({ }_{40} q_{20}\right)$ & 0.326 & 0.321 & 0.310 & 0.357 & 0.321 & 0.350 \\
\hline \multicolumn{7}{|l|}{ Russians } \\
\hline Alcohol consumption (mL) & 738 & 783 & 1088 & 852 & 665 & 746 \\
\hline Per cent speak Kazakh & 6.43 & 1.37 & 17.76 & 5.95 & 0.73 & 2.13 \\
\hline Per cent college educated & 9.3 & 8.6 & 11.6 & 8.4 & 8.1 & 8.4 \\
\hline (2) Adult mortality $\left({ }_{40} q_{20}\right)$ & 0.413 & 0.431 & 0.385 & 0.486 & 0.405 & 0.415 \\
\hline \multirow[t]{2}{*}{ Ratio $(2) /(1)$} & 1.264 & 1.342 & 1.244 & 1.359 & 1.263 & 1.186 \\
\hline & \multicolumn{6}{|c|}{ Females, by region } \\
\hline \multicolumn{7}{|l|}{ Kazakhs } \\
\hline Alcohol consumption (mL) & 230 & 175 & 326 & 343 & 220 & 179 \\
\hline Per cent speak Russian & 90.22 & 95.53 & 87.27 & 82.33 & 98.20 & 96.56 \\
\hline Per cent college educated & 10.7 & 12.9 & 11.7 & 8.6 & 8.9 & 8.9 \\
\hline (3) Adult mortality $\left({ }_{40} q_{20}\right)$ & 0.152 & 0.135 & 0.156 & 0.153 & 0.149 & 0.157 \\
\hline \multicolumn{7}{|l|}{ Russians } \\
\hline Alcohol consumption (mL) & 205 & 197 & 131 & 187 & 220 & 209 \\
\hline Per cent speak Kazakh & 5.35 & 1.07 & 14.56 & 5.03 & 0.63 & 1.73 \\
\hline Per cent college educated & 11.5 & 10.6 & 14.1 & 11.2 & 9.8 & 10.4 \\
\hline (4) Adult mortality $\left({ }_{40} q_{20}\right)$ & 0.166 & 0.176 & 0.157 & 0.189 & 0.163 & 0.163 \\
\hline Ratio $(4) /(3)$ & 1.091 & 1.304 & 1.009 & 1.235 & 1.098 & 1.038 \\
\hline
\end{tabular}

Note: Alcohol converted to $\mathrm{mL}$ per person consumed per month. Currency value converted to 2012 USD. See Figure 1 for oblasts by region. 'Kazakh' refers to all Central Asians in Kazakhstan; 'Russian' refers to the Slavic population of Kazakhstan.

Source: LSMS (alcohol and spending); Kazakh 1999 Census (population, language, education) Kazakhstan vital statistics 1998-99 (mortality). 
Table 2:

Age-standardised death rate (per 100,000) at ages 20-59 $\left(40 M_{20}\right)$, by sex, ethnicity and cause of death, Kazakhstan, 1998-1999

\begin{tabular}{|c|c|c|c|c|c|}
\hline \multirow[b]{2}{*}{ Cause of death } & \multirow{2}{*}{$\begin{array}{c}\text { Russian } \\
\text { (1) }\end{array}$} & \multirow{2}{*}{$\begin{array}{c}\text { Kazakh } \\
\text { (2) }\end{array}$} & \multicolumn{2}{|c|}{ Gap } & \multirow{2}{*}{$\begin{array}{l}\text { Ratio } \\
\text { (1)/(2) }\end{array}$} \\
\hline & & & (1)-(2) & $\%$ & \\
\hline & \multicolumn{5}{|c|}{ Males } \\
\hline All causes & 1465.5 & 1019.2 & 446.3 & 100.00 & 1.44 \\
\hline Infectious and parasitic diseases & 134.8 & 91.3 & 43.5 & 9.75 & 1.48 \\
\hline Neoplasms & 184 & 136.6 & 47.4 & 10.62 & 1.35 \\
\hline Diseases of the circulatory system & 462.3 & 376.8 & 85.5 & 19.16 & 1.23 \\
\hline Diseases of the respiratory system & 82.2 & 54.4 & 27.8 & 6.23 & 1.51 \\
\hline Diseases of the digestive system & 66.7 & 55.8 & 10.9 & 2.44 & 1.20 \\
\hline External causes & 435.1 & 232.2 & 202.9 & 45.46 & 1.87 \\
\hline Other causes & 100.4 & 72.1 & 28.3 & 6.34 & 1.39 \\
\hline Directly alcohol related causes & 51.1 & 9.9 & 41.2 & 9.23 & 5.16 \\
\hline \multirow[t]{2}{*}{ All Causes related to alcohol consumption } & 986.4 & 584.6 & 401.8 & 90.03 & 1.69 \\
\hline & \multicolumn{5}{|c|}{ Females } \\
\hline All Causes & 477.9 & 414.2 & 63.7 & 100.00 & 1.15 \\
\hline Infectious and Parasitic diseases & 16.3 & 29.0 & -12.7 & -19.94 & 0.56 \\
\hline Neoplasms & 111.6 & 82.7 & 28.9 & 45.37 & 1.35 \\
\hline Diseases of the circulatory system & 168.3 & 165.8 & 2.5 & 3.92 & 1.02 \\
\hline Diseases of the respiratory system & 17.5 & 22.9 & -5.4 & -8.48 & 0.76 \\
\hline Diseases of the digestive system & 24.3 & 25.7 & -1.4 & -2.20 & 0.95 \\
\hline External causes & 93 & 43.2 & 49.8 & 78.18 & 2.15 \\
\hline Other causes & 46.9 & 44.9 & 2.0 & 3.14 & 1.04 \\
\hline Directly alcohol related causes & 13.9 & 1.7 & 12.2 & 19.15 & 8.18 \\
\hline All causes related to alcohol consumption & 220.5 & 166.0 & 54.5 & 85.56 & 1.33 \\
\hline
\end{tabular}

Note: 'Kazakhs' includes ethnic Kazakhs (98.3\%), Kyrgyz, Uzbeks, Tajiks and Turkmen. 'Russians' includes Russians (82.9\%), Ukrainians and Belorussians. Totals may not sum to 100 due to rounding. Directly alcohol related causes include: alcohol poisoning, alcohol cirrhosis of the liver, alcohol psychosis and chronic alcoholism. Causes indirectly related to alcohol consumption from Zaridze et al. (2009b). Detailed causes in the appendix Table A.1.

Source: Author's calculation based on Kazakhstan 1999 Census data and 1998-1999 vital registration data.

be associated with misclassified alcohol poisoning; see Zaridze et al. (2009a) for a full list and discussion. For example, Russian men have significantly higher death rates from myocardial infarction, ischemic heart disease and related conditions that may have underlying behavioural causes related to diet and alcohol consumption. Tuberculosis (TB) is another notable condition, explaining 9-10 per cent of the ethnic gap for males. TB infection in the Russian population has been linked to incarceration (Bobrik et al. 2005), and the result is sensible when considering that alcohol is associated with crimes that are more likely to result in jail time (Gavrilova et al. 2005). 
Mortality from the directly related causes is 5 times greater for Russian males than for Kazakhs. This compares to 14 times greater alcohol mortality in Kyrgyzstan. The larger Russian-Kyrgyz mortality gap is partially due to lower rates among Kyrgyz than among Kazakhs, but also to the higher rate of alcohol mortality among Kyrgyzstani Russian males (83.0 deaths per 100,000) than among Kazakhstani Russians (51.1 per 100,000). The reason for the lower rate among Russians is unknown; it may represent some degree of diffusion of behavioural norms from Kazakhs to Russians facilitated by more Russian fluency among Kazakhs, although there is insufficient evidence here to make that case. It is a potentially significant finding, given the overall high degree of similarity between Russians in the two countries. Alcohol poisoning alone accounts for 7 per cent of the total male mortality gap by ethnicity in Kazakhstan: consistent with the theory, this is lower than the ratio for Russians to Kyrgyz, which explains 12 per cent of the gap in Kyrgyzstan.

The story is similar for females, although Central Asian females have dramatically lower levels of alcohol-related deaths than Central Asian males: the ratio of male to female deaths for these causes is approximately 6:1 in Kazakhstan and 8.5:1 in Kyrgyzstan.

The Russian mortality paradox applies to both sexes. In Kyrgyzstan, the gap between Kyrgyzstani Russian and Kyrgyz men appears to be greater than the same gap for women (Guillot et al. 2011a). The results in Kazakhstan are consistent with this pattern. Female mortality for all groups is around one-third to one-half the male level, and female mortality directly attributable to alcohol is closer to one-fourth the male level in both countries for Russians, while lower still for Central Asians. It is evident that alcohol plays a significant role here, although through a somewhat different profile of causes by sex. External causes are a greater share of the mortality gap for females than for males, at fully $78.2 \%$, partly explained by the very low rates of violent death (except suicides) among Central Asian women. Infectious disease mortality is lower among Russian females than their Kazakh counterparts, contrary to the findings for males. This could be a result of lower tuberculosis rates among Russian women. Men may be more likely to have conflicts erupt in violence and end with arrest, which would explain why the link between alcohol consumption and tuberculosis is not found for women. Cancer mortality is higher for Russian females; however, upper digestive tract cancers that can result from chronic alcoholism do not account for the difference.

Physical manifestations of chronic alcohol abuse such as upper digestive tract cancers and liver cirrhosis are not dramatically higher among Russians. This is consistent with the findings from studies of alcohol abuse that it is not only a high volume of alcohol that can adversely affect health, but also the manner in which it is consumed. Binge drinking can result in increased mortality from external causes without signs of chronic alcoholism, and data from Russia show that such sporadic bouts of heavy drinking are normal (Shkolnikov and Nemtsov 1994) and associated with higher mortality risk (Brainerd and Cutler 2005; Denisova 2009). Overall, it is psychological and circumstantial factors associated with sporadic, heavy 
drinking — overdose, violence and accidents relating to alcohol consumption-where the disparity between Kazakhs and Russians is greatest.

Deaths directly attributable to chronic and acute alcohol consumption (four causes out of a list of 200) account for 9\% of the male mortality gap, and excess mortality among Russians to causes "strongly related to alcohol consumption" (Zaridze et al. 2009 b) accounts for fully $90 \%$. For females, direct causes account for $20 \%$ of the gap and direct plus indirect causes account for $85 \%$.

Comparing the Kazakhstan results with those for Kyrgyzstan, directly alcoholattributable deaths account for a larger share of the gap between Russians and Central Asians in Kyrgyzstan (15\% for males and 37\% for females), reflecting greater alcoholrelated mortality for both Kazakhs (compared to Kyrgyz) and Kyrgyzstani Russians (compared to Kazakhstani Russians). Kazakhs have significantly greater alcohol related mortality than other Central Asians. Kazakh mortality for males and females is higher overall, but would be closer to parity if the levels of alcohol related deaths were identical.

Kazakhs share linguistic and cultural affinities with both Russia and Kyrgyzstan, and are situated in between Russians and Kyrgyz in terms of their mortality levels. The evidence is consistent with an interpretation of the Russian mortality paradox as a gradient, along which closer affinity to Russian language and customs (related to some degree to eating and drinking habits) result in mortality patterns approaching the Russian standard. As seen in Figure 2, the ratio of alcohol-related mortality to all-cause mortality for Kazakh men is higher in areas where there are greater concentrations of Russians.

The next section will test the robustness of these associations in a multivariate regression of mortality on ethnicity and a set of demographic and socioeconomic variables.

\subsection{Multivariate regression}

The comparison of cause of death data above addresses differences in age structure, but not the possibility that the mortality gap is driven by the differences in the environments in which Slavs and Central Asians live. Kazakhstan is an ideal choice to test the influence of geography and economic context because - unlike Kyrgyzstanthere is a significant rural population of Russians dispersed across the country as well as a large number of urban and russified Central Asians.

From the death rates dataset, we constructed an analytic sample of deaths by age, ethnicity, sex and geography (urban/rural and oblast). We excluded non-Slavic and non-Asian ethnicities and ages below 20 or over 59. Since these data are geographically specific, we can include contextual variables that exist in only one dataset or external sources, as long as they can be linked by geography. The linguistic russification is the only such variable used at present. We also tried employment and consumption measures, but they were not statistically significant after the controls already used, and did not affect the results. Linguistic russification is defined as the 
per cent of the Kazakhs in the local area (by urban/rural residence within the oblast or oblast-level city) who speak fluent Russian. A plot of this variable against the standardised adult mortality rate is included in the appendix (Figure A.1). The key regression results are presented in Table 4. Models 1 through 3 test the robustness of the Russian ethnic mortality disadvantage, and models 3 and 4 test the effect of Russian fluency at the local (oblast by urban/rural residence) level. Model 4 includes Kazakhs only.

The first model, with only age group and oblast controlled, estimates a mortality ratio of 1.45 for Slavic to Asian males, and 1.17 for females (agreeing closely with the descriptive analysis). Accounting for differences between urban and rural areas and by education level reduces the ratio to 1.27 for males and leaves the results for females virtually unchanged. Residential patterns and educational differences between the two groups explains approximately half of the excess mortality of Slavic males, and little to none of the gap for females. The gap of approximately one fourth higher mortality among Russian men remains unexplained.

The unit of the Russian fluency variable is a standard deviation (approximately 8 per centage points). Independently, living in a russified area is a significant predictor of increased mortality. In unit terms, a per centage point increase in the local area level of Russian fluency among Kazakhs is associated with an increase in the mortality hazard by 2 per centage points. The mortality gap for females is smaller to begin with, and more difficult to explain - the available contextual variables explain very little of the raw Slavic coefficient. The russification variable is significant and positive, although the effect for women is less than one half the size as the effect for men. The effect on Kazakh women is insignificant, suggesting that Kazakh women are the only population not worse off in russified areas. This effect has not been previously observed, and it remains to be determined what pattern of social interaction could explain this finding. One possibility compatible with the social networking theory is that there is less interaction between Russians and Kazakh women compared to Russians with Kazakh men, and that interactions between Kazakh men and Kazakh women are more likely to be conducted in Kazakh language. Tabulations from the 1999 Census (not shown) confirm that the rates of Russian fluency among Kazakhs is lower among women than among men.

The russification variable is likely standing in as a proxy for unobserved behavioural differences between Kazakhs in areas where Russian is more or less widely spoken. In this sense, it is proxying for more than just the prevalence of Russian custom and habit. The argument about russification is at some point a qualitative one; what should and shouldn't be controlled for to get a 'better' estimate of russification? A better discussion about how to measure the propagation of Russian habits is a necessity before gains can be made with this modelling strategy.

We are also interested in confirming the ethnic differential in cause-specific mortality rates. We use the same approach as in model 2 of Table 3 , for main categories of causes of death and for alcohol-related causes. We report the results of the first two models for each sex in Table 4. The table reports exponentiated 


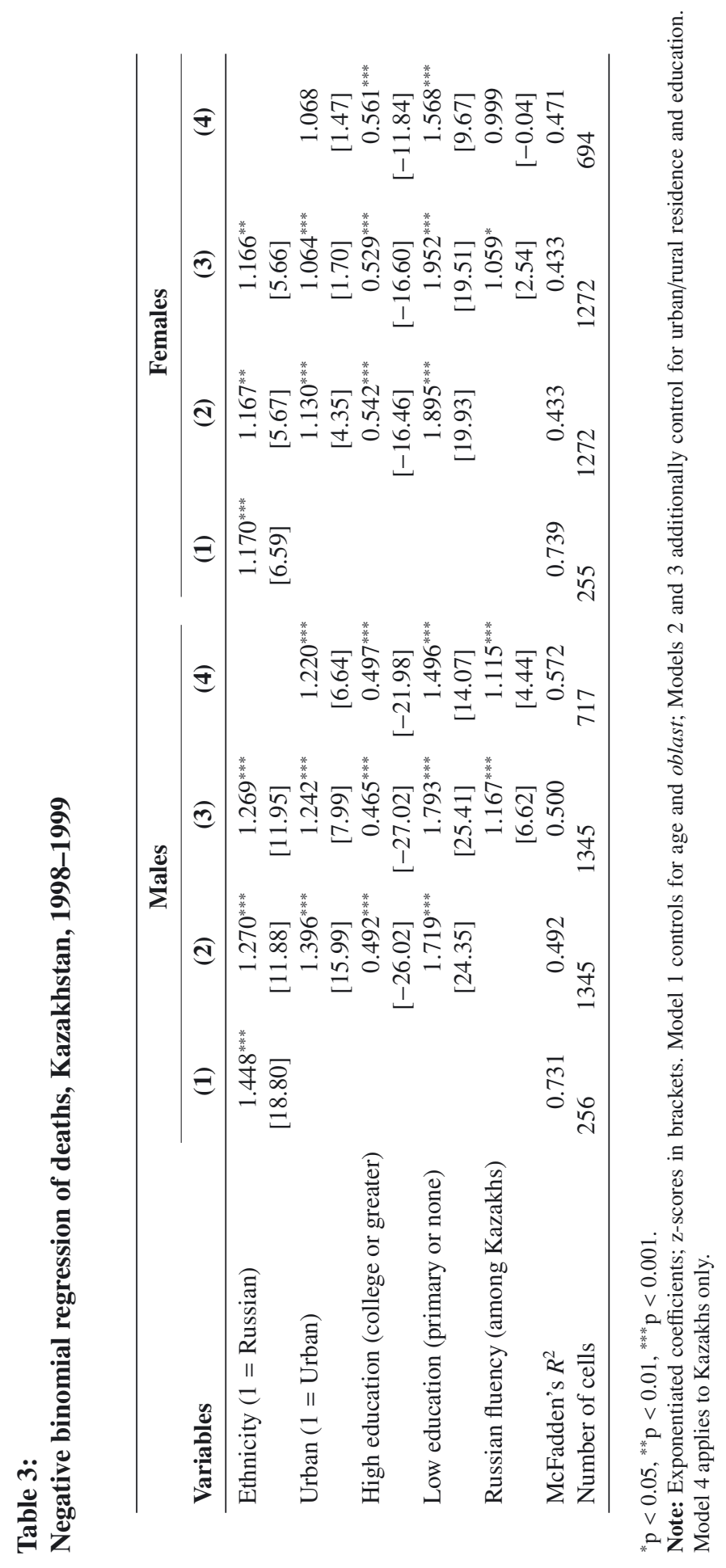


Table 4:

Negative binomial regressions of deaths by cause on Russian ethnicity, Kazakhstan, 1998-1999

\begin{tabular}{lccccc}
\hline & \multicolumn{2}{c}{ Males } & & \multicolumn{2}{c}{ Females } \\
\cline { 2 - 3 } \cline { 5 - 6 } Cause of death & $(\mathbf{1})$ & $(\mathbf{2})$ & & $(\mathbf{1})$ & $(\mathbf{2})$ \\
\hline All causes & $1.448^{* * *}$ & $1.270^{* * *}$ & & $1.170^{* * *}$ & $1.167^{* * *}$ \\
& {$[18.80]$} & {$[11.88]$} & & {$[6.59]$} & {$[5.67]$} \\
Infectious and parasitic diseases & $1.341^{*}$ & 0.872 & & $0.555^{* * *}$ & $0.437^{* * *}$ \\
& {$[2.23]$} & {$[-1.41]$} & & {$[-3.30]$} & {$[-5.33]$} \\
Neoplasms & 1.305 & 1.037 & & 1.180 & 1.087 \\
& {$[1.77]$} & {$[0.35]$} & & {$[1.07]$} & {$[0.79]$} \\
Diseases of the circulatory system & 1.085 & 0.935 & & 0.860 & 0.836 \\
& {$[0.62]$} & {$[-0.83]$} & & {$[-1.03]$} & {$[-1.84]$} \\
Diseases of the respiratory system & $1.416^{*}$ & 1.017 & & 0.717 & $0.560^{* * *}$ \\
Diseases of the digestive system & {$[2.16]$} & {$[0.14]$} & & {$[-1.69]$} & {$[-3.40]$} \\
& 1.289 & 1.027 & & 0.944 & 0.800 \\
External causes & {$[1.54]$} & {$[0.21]$} & & {$[-0.30]$} & {$[-1.35]$} \\
& $1.528^{* * *}$ & $1.222^{* *}$ & & $1.765^{* * *}$ & $1.510^{* * *}$ \\
Other causes & {$[3.91]$} & {$[2.90]$} & & {$[4.07]$} & {$[3.94]$} \\
& 1.177 & 0.917 & & 0.873 & $0.767^{*}$ \\
Directly alcohol-related causes & {$[1.16]$} & {$[-0.84]$} & & {$[-0.89]$} & {$[-2.26]$} \\
& $3.693^{* * *}$ & $2.504^{* * *}$ & & $5.460^{* * *}$ & $4.122^{* * *}$ \\
Indirectly alcohol-related causes & {$[6.21]$} & {$[5.08]$} & & {$[5.02]$} & {$[4.45]$} \\
& $1.426^{* * *}$ & $1.135^{*}$ & & 1.177 & 1.075 \\
& {$[3.51]$} & {$[2.13]$} & & {$[1.34]$} & {$[0.89]$} \\
\hline
\end{tabular}

${ }^{*} \mathrm{p}<0.05,{ }^{* *} \mathrm{p}<0.01,{ }^{* * *} \mathrm{p}<0.001$.

Note: Exponentiated coefficients; z-scores in brackets. Model 1 controls for age and oblast; Model 2 additionally controls for urban/rural residence and education. Coefficients refer to Russian ethnicity dummy with Kazakhs as reference category.

coefficients for the Russian ethnicity dummy under two models for each of the top-level causes.

Controls for education, oblast and urban/rural location explain half of the all-cause mortality gap for males, which falls from approximately $50 \%$ higher for Russians to just $27 \%$. However, the controls explain very little of the female gap, which remains near 17\%. Comparing the results of Model 2 to the cause of death analysis in Table 2, contextual differences explain a large share of the ethnic mortality gap for men and an insignificant share of the gap for women. They explain approximately half of the variation in alcohol-related mortality for both sexes. The ratio of Slavic to Central Asian mortality from alcohol-related causes falls from 5 to 2.5 for men and from 8 to 4 for women. 
For Russian males, the apparently higher rates of infectious disease mortality and death from respiratory ailments are not significant after controls. The difference in allcause mortality is driven by the family of causes that are directly or indirectly alcoholrelated (most of the external causes of death, which are also highly significantly different, are included in the latter list). For women, the earlier finding of lower rates of deaths from infectious and parasitic diseases among Russians is robust, and in fact mortality of Russian women from respiratory diseases and other causes are both significantly lower than the rates for Kazakh women after controls. The areas where Russian women are worse off than Kazakh women are concentrated in the same causes as men; the gap is even higher between Russian and Kazakh women than among men, but on balance the gap in all-cause mortality is lower because of the mortality advantage enjoyed by Russian women in other causes unrelated to alcohol consumption.

For men and women, external causes of death are much higher for Russians. After controls, Russian men are $22 \%$ more likely to die from this family of causes than Kazakh men, and Russian women 51\% more likely than Kazakh women. Russian men are two and a half times more likely to die of alcohol-related poisoning, cirrhosis, psychosis and chronic alcoholism, and Russian women are more than four times more likely than Kazakh women to die of the same causes. The gap in indirectly alcohol-related causes shrinks considerably with the addition of controls. This broad group of causes remains an important factor in explaining the mortality gap for males, but mortality rates for females from these causes as a group are no longer significantly different between Russian and Kazakh females.

\section{Conclusion}

The Russian mortality penalty has shown itself to be robust to the major contextual differences between Kazakhs and Russians. The concentration of excess Russian mortality in causes related to alcohol abuse is consistent with prior findings, and in the hypothesised direction. Crucially, Kazakh mortality exceeds that of Kyrgyz in alcohol-related causes of death-further evidence of the role of alcohol in post-Soviet mortality contexts.

This paper is the first to study detailed causes by ethnicity for Kazakstan during the period of the 1999 Census. The adult mortality of Russian men is $45 \%$ higher than for Kazakhs. Russians and Kazakhs live in different areas of the country, and live different lifestyles. Controlling for contextual differences, Russian men's allcause mortality remains $27 \%$ higher, and alcohol-related deaths among Russians men remain 2.5 times higher. There is no significant mortality differential between Russian and Kazakh men for most causes of death, but external causes and alcohol-related causes are large exceptions which explain the vast majority of the ethnic mortality gap. Russian women similarly have higher all-cause mortality, although only $15 \%$ higher than Kazakh women. The excess all-cause mortality of Russian women is unchanged when controls are included. Russian women have lower likelihood of 
dying from infectious or parasitic diseases or respiratory diseases, and much higher likelihood of dying due to external or alcohol-related causes. The alcohol-related death rate remains 4.1 times higher for Russian women relative to Kazakh women.

In the analysis, we present an original test for significantly higher mortality as an consequence of russification. The gradient observed between Russians, Kazakhs and Kyrgyz in direct mortality estimation hints at closeness to Russian cultural habits as a driver of increased adult mortality. Living in russified locations is associated with higher adult mortality risk for Russians and for Kazakh men (approximately $2 \%$ pt. increase in mortality rates for each $1 \%$ pt. increase in Russian fluency among Kazakhs), but Kazakh women appear to be insulated from the process that generates this association.

The Slavic-Asian gap in socioeconomic status in Kazakhstan is lower than in Kyrgyzstan. Since the Kazakhs have greater education and consumption levels than Kyrgyz, one would expect their mortality levels to be better overall-which they are generally, with the glaring exception being worse rates the same causes of death that happen to explain Russia's poor adult mortality. In other words, higher socioeconomic status among Kazakhs does not necessarily translate to better health, since Kazakhs also tend to be more russified, and fall prey to the same problems that Avdeev et al. (1998) called the 'specific nature of Russian mortality'.

The results beg the larger question of why russification should lead to worse health. There have been some suppositions about why there has been such a rapid growth in alcohol-related mortality among adult Russians in the former Soviet sphere, but there is as yet no scientific consensus. Blum related the increase in adult mortality with the failure of the state to bolster the 'attitudes, outlooks and hopes' of individuals; profound disillusionment with the Soviet vision of the future could explain both the end of the Soviet Union and the health crisis in one stroke (Blum 1994; Eberstadt 1995). This paper has contributed to understanding the nature of the problem, establishing that Kazakhstani Russians exhibit the same mortality patterns as Russians elsewhere, and that the Russian pattern of mortality is also to some extent visible in the Kazakh population. The former Soviet bloc still accounts for a significant share of the world population, suggesting an urgency to understanding what precisely precipitated the alcohol-fueled increase in mortality in the Russianspeaking world.

\section{Acknowledgements}

The authors are grateful to Marc Luy, Herbert L. Smith and Emily Hannum for helpful advice and suggestions, as well as two anonymous referees.

\section{Appendix}




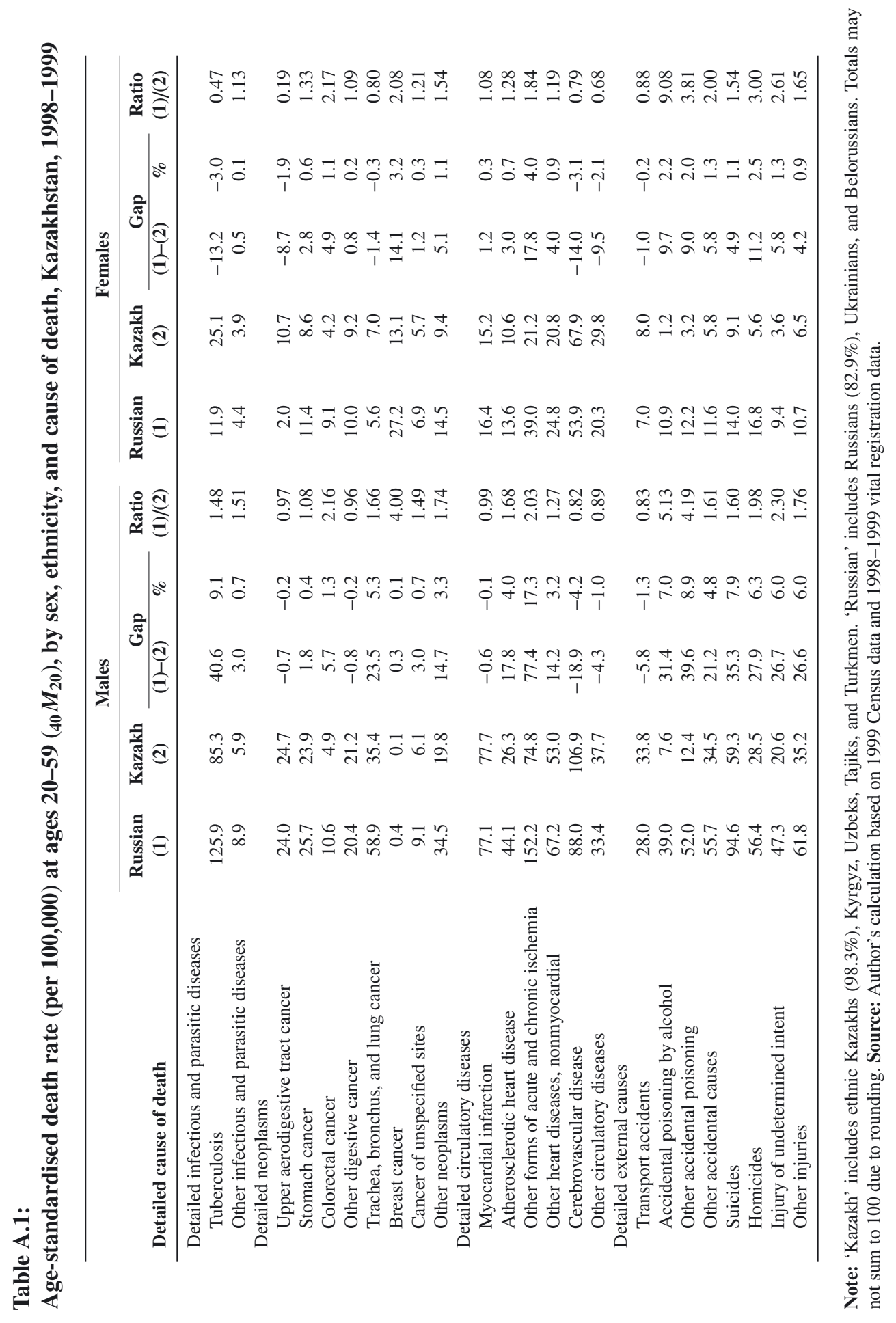


Figure A.1:

Adult mortality rates according to oblast-level russification, Kazakhstan 1998-1999
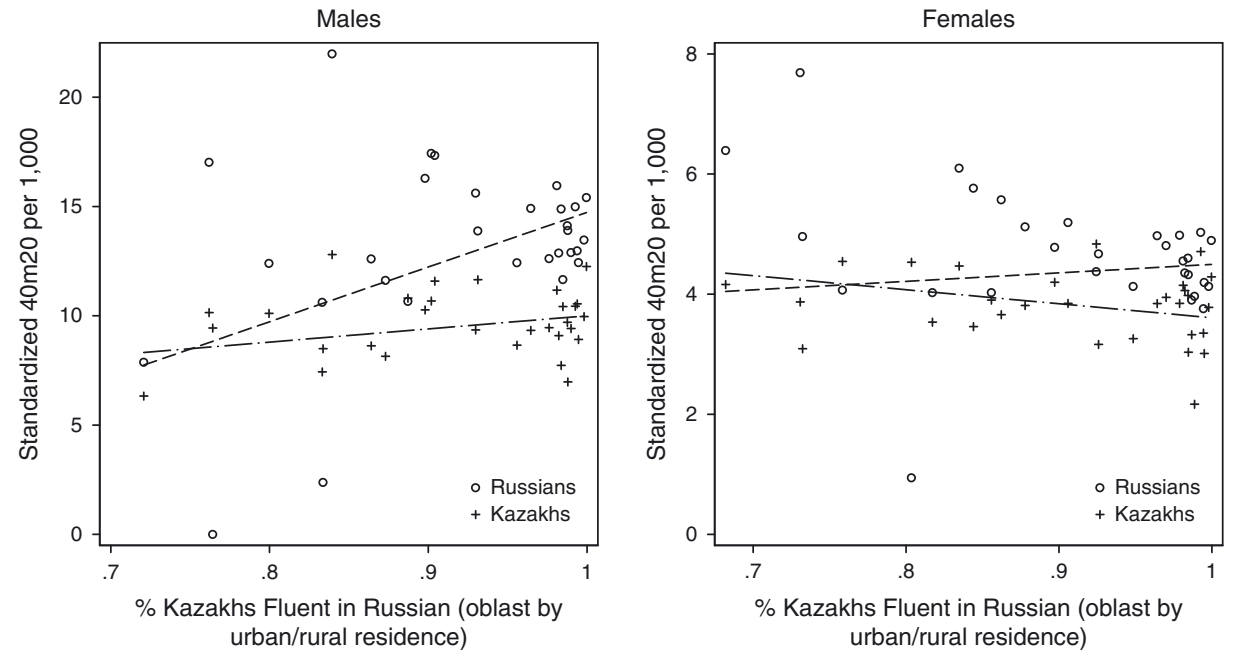

Note: Rates shown as $40 m_{20}$, death rates per 1,000 population between age 20 to 60 .

Source: Kazakhstan 1999 Census and Kazakhstan vital registration system 1998-1999.

\section{References}

Abbot, P. 2003. Living Conditions, Lifestyles, and Health in Armenia, Belarus, Georgia, Kazakhstan, Kyrghyzstan, Moldova, Russia \& Ukraine: Social Trends 1990-2002. Working Paper. Vienna: Institute for Social Research.

Agadjanian, V., and P. Dommaraju. 2006. Reproduction in Upheaval: Ethnicity, Fertility, and Societal Transformations in Kazakhstan. Presented at the Annual Meeting of the Population Association of America, Los Angeles, 30 March - 1 April 2006.

Aisagalieva, S. 1999. The Using of Information Technologies in the First National Census of the Population of Independent Kazakhstan. Paper presented at UNESCAP Seminar on Application of Information Technology in National Statistical Offices, Taejon.

Anderson, B., and B. Silver. 1983. "Estimating Russification of Ethnic Identity Among Non-Russians in the USSR". Demography 20 (4): 461-489.

Anderson, B., and B. Silver. 1990. "Some Factors in the Linguistic and Ethnic Russification of Soviet Nationalities: Is Everyone Becoming Russian?" In Some Factors in the Linguistic and Ethnic Russification of Soviet Nationalities: Is Everyone Becoming Russian?, ed. by L. Hajda and M. Beissinger. Boulder, CO: Westview Press. 
Anderson, B., and B. Silver. 1997. "Issues of Data Quality in Assessing Mortality Trends and Levels in the New Independent States". In Premature Death in the New Independent States, ed. by N. R. Council. Washington, DC: National Academy Press.

Andreev, E., S. Scherbov, and F. Willekens. 1995. Sources of Information on the Population of Russia. Working Paper. Faculty of Spatial Sciences, University of Groningen.

Aristov, N. 1896. Zametki ob ethnicheskom sostave tiurkskikh plemen i narodnostei $i$ Svedeniia ob ikh chislennosti. St. Petersburg: Zhivaia starina.

Avdeev, A., A. Blum, S. Zakharov, and E. Andreev. 1998. "The Reactions of a Heterogeneous Population to Perturbation: An Interpretative Model of Mortality Trends in Russia”. Population (English Edition) 10: 267-302.

Becker, C., and D. Urzhumova. 2005. "Mortality Recovery and Stabilization in Kazakhstan, 1995-2001”. Economics E Human Biology 3 (1): 97-122.

Blum, A. 1994. Naître, vivre et mourir en URSS. Paris: Plon.

Bobrik, A., K. Danishevski, K. Eroshina, and M. McKee. 2005. "Prison Health in Russia: The Larger Picture". Journal of Public Health Policy 26: 30-59.

Bougdaeva, S. 2010. "The Russian Puzzle: Mortality and Ethnicity in a Changing Society, 1994 -2004”. Communist and Post-Communist Studies 43: 325-333.

Brainerd, E. 2010. "Reassessing the Standard of Living in the Soviet Union: An Analysis Using Archival and Anthropometric Data". Journal of Economic History $70(1)$

Brainerd, E., and D. Cutler. 2005. "Autopsy on an Empire: Understanding Mortality in Russia and the Former Soviet Union". Journal of Economic Perspectives 19 (1).

Cameron, C., and P. Trevedi. 1990. "Regression Based Tests for Overdispersion in the Poisson Model”. Journal of Econometrics 46: 347-364.

Chen, L., F. Wittgenstein, and E. McKeon. 1996. “The Upsurge of Mortality in Russia: Causes and Policy Implications". Population and Development Review 22 (3): 517-530.

Cleland, J., and C. Wilson. 1987. "Demand Theories of the Fertility Transition: An Iconoclastic View”. Population Studies 41 (1): 5-30.

Cockerham, W., B. Hinote, P. Abbott, and C. Haerpfer. 2004. "Health Lifestyles in Central Asia: The Case of Kazakhstan and Kyrgyzstan”. Social Science and Medicine 59 (7): 1409-1420.

Dave, B. 1996. "National Revival in Kazakhstan: Language Shift and Identity Change". Post-Soviet Affairs 12 (1): 51-73.

Dave, B. 2004. Minorities and Participation in Public Life: Kazakhstan. Paper presented at UNHCR Seminar on Cultural Diversity and Development in Central Asia, Bishkek. 
Dave, B., and P. Sinnott. 2002. Demographic and Language Politics in the 1999 Kazakhstan Census. Working paper. National Council for Eurasian and East European Research.

Dave, B. 2007. Kazakhstan: Ethnicity, Language and Power. Psychology Press.

Denisova, I. 2009. Mortality in Russia: Microanalysis. Working Paper 128. Center for Economic and Financial Research.

Eberstadt, N. 1995. "The Soviet Way of Death". World Affairs 158 (2): 100-105.

Edelbay, S. 2012. “Traditional Kazakh Culture and Islam”. International Journal of Business and Social Science 3 (11).

Edgar, A. 2007. "Marriage, Modernity, and the "Friendship of Nations": Interethnic Intimacy in Post-War Central Asia in Comparative Perspective". Central Asian Survey 26 (4): 581-599.

Gavrilova, N. S., L. A. Gavrilov, V. Semyonova, G. Evdokushkina, and A. Ivanova. 2005. "Patterns of Violent Crime in Russia". In Ruling Russia: Law, Crime, and Justice in a Changing Society. Boulder, CO: Rowman \& Littlefield.

Gavrilova, N. S., V. Semyonova, G. Evdokushkina, and L. A. Gavrilov. 2000. "The Response of Violent Mortality to Economic Crisis in Russia". Population Research and Policy Review 19: 397-419.

Gorenburg, D. 2006. "Rethinking Interethnic Marriage in the Soviet Union". PostSoviet Affairs 22 (2): 145-165.

Guillot, M., N. Gavrilova, and T. Pudrovska. 2011a. "Understanding the "Russian Mortality Paradox" in Central Asia: Evidence From Kyrgyzstan". Demography 48 (3): 1081-1104.

Guillot, M., N. Gavrilova, L. Torgashova, and M. Denisenko. 2011b. Mortality in Central Asia Before and After the Break-Up of the Soviet Union: Evidence From Kyrgyzstan. Paper presented at Moscow Higher School of Economics XII April Conference on Modernization of Economy and Society.

Hopkirk, P. 1992. The Great Game: The Struggle for Empire in Central Asia. Kodansha International.

Hopkirk, P. 1995. Setting the East Ablaze: Lenin's Dream of an Empire in Asia. Kodansha International.

Kazakhstan Statistics. 2000a. Census of Kazakhstan 1999. Agency of Statistics of the Republic of Kazakhstan.

Kazakhstan Statistics. 2000b. Death Certificates 1998-1999. Agency of Statistics of the Republic of Kazakhstan.

Kazakhstan Statistics. 2010. Kazakhstan Statistical Yearbook 2009. Agency of Statistics of the Republic of Kazakhstan.

Knodel, J., and E. van den Walle. 1979. "Lessons From the Past: Policy Implications of Historical Fertility Studies". Population and Development Review 5 (2): $217-245$. 
Lesthaeghe, R. 1977. The Decline of Belgian Fertility, 1800-1970. Princeton University Press.

Masanov, N., E. Karin, A. Chebotarev, and N. Oka. 2002. The Nationalities Question in Post-Soviet Kazakhstan. Working Paper. JETRO.

Mathers, C. D., D. M. Fat, M. Inoue, C. Rao, and A. D. Lopez. 2005. "Counting the Dead and What They Died From: An Assessment of the Global Status of Cause of Death Data". Bulletin of the World Health Organization 83: 171-177.

Meyer, K., and S. Brysac. 2006. Tournament of Shadows: The Great Game and the Race for Empire in Central Asia. Basic Books.

Peyrouse, S. 2008. The Russian Minority in Central Asia: Migration, Politics and Language. Working Paper. Woodrow Wilson International Center for Scholars.

Pomerleau, J., M. McKee, R. Rose, C. Haerpfer, D. Rotman, and S. Tumanov. 2005. "Drinking in the Commonwealth of Independent States? Evidence From Eight Countries". Addiction 100 (11).

Radlov, V. V. 1989. Iz Sibirii: Stranitsi dnevnika. Moscow.

Rehm, J., R. Room, M. Monteiro, G. Gmel, K. Graham, N. Rehn, C. Sempos, U. Frick, and D. Jernigan. 2004. "Alcohol Use". In Comparative Quantification of Health Risks: Global and Regional Burden of Disease Attributable to Selected Major Risk Factors, ed. by M. Ezzati, A. Lopez, A. Rodgers, and C. J. L. Murray, vol. 1. Geneva: World Health Organization.

Salhani, C. 2011. Islam Without a Veil: Kazakhstan's Path of Moderation. Potomac Books.

Shkolnikov, V. M., and A. Nemtsov. 1994. The Anti-Alcohol Campaign and Variations in Russian Mortality. Paper presented at the Seminar on mortality and adult health priorities in the New Independent States, Centre for Demography and Ecology, University of Washington.

Smith, K., and N. Christakis. 2008. "Social Networks and Health". Annual Review of Sociology 34: 405-429.

The World Bank. 1996. Living Standards Measurement Study (LSMS).

Tynystanova, A. 2002. Russification and Its Consequences in Kazakhstan. Working Paper. Libertas.

Wasserman, D., and A. Varnik. 2007. "Suicide-Preventive Effects of Perestroika in the Former USSR: The Role of Alcohol Restriction". Psychiatrica Scandinavica 98 (S394): 1-4.

Waters, E., and B. Thom. 2007. "Alcohol, Policy and Politics in Kazakhstan". EuropeAsia Studies 59 (6): 999-1023.

WHO. 1999. Highlights on Health in Kazakhstan. World Health Organization.

Willekens, F., and S. Scherbov. 1992. "Analysis of Mortality Data From the Former USSR: Age-Period-Cohort Analysis". World Health Statistics 45: 29-49. 
Zaridze, D., P. Brennan, J. Boreham, A. Boroda, R. Karpov, A. Lazarev, and R. Peto. 2009a. "Alcohol and Cause-Specific Mortality in Russia: A Retrospective CaseControl Study of 48,557 Adult Deaths". The Lancet 373: 2201-2214.

Zaridze, D., D. Maximovitch, A. Lazarev, V. Igitov, A. Boroda, J. Boreham, and P. Boffetta. 2009b. "Alcohol Poisoning Is a Main Determinant of Recent Mortality Trends in Russia: Evidence From a Detailed Analysis of Mortality Statistics and Autopsies". International Journal of Epidemiology 38: 143-153. 